\title{
Qualidade recreacional e capacidade de carga das praias do litoral norte do estado da Bahia, Brasil *
}

\author{
Recreational quality and carrying capacity of \\ Babia State Northern coast beaches, Brazil
}

\author{
Iracema Reimão Silva ${ }^{\circledR, 1}$, Abílio Carlos da Silva Pinto Bittencourt ${ }^{2}$, \\ J. A. Dias ${ }^{3}$, José Rodrigues de Souza Filho ${ }^{4}$
}

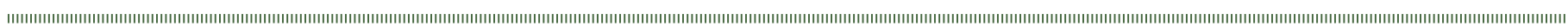

\section{RESUMO}

O litoral norte do estado da Bahia compreende sete municípios - Lauro de Freitas, Camaçari, Mata de São João, Entre Rios, Esplanada, Conde e Jandaíra - em aproximadamente $200 \mathrm{~km}$ de litoral. Os três primeiros apresentam um litoral com urbanização consolidada ou em processo de consolidação, já os demais, apresentam, na maioria de sua extensão, praias desertas ou semi-desertas, com pouca ou nenhuma urbanizaçáo do seu litoral. Este trabalho teve como objetivo avaliar a qualidade recreacional e a capacidade de carga das praias do litoral norte da Bahia, bem como os seus limites ecológicos, oferecendo subsídios aos planos de uso e ocupação deste litoral. A qualidade recreacional das praias estudadas foi avaliada a partir da análise de 20 (vinte) indicadores de qualidade geoambiental e 12 (doze) de infraestrutura, classificados em diferentes graus de atratividade. De acordo com o método de estudo empregado, as praias de Vilas do Atlântico, Buraquinho, Itacimirim, Praia do Forte, Imbassaí e Subaúma foram classificadas como de alta qualidade recreacional, e as praias de Busca Vida, Interlagos, Santo Antônio, Porto Sauípe, Massarandupió, Baixio e Sitio do Conde como de baixa qualidade recreacional. No primeiro caso, a maior parte das praias apresentou zonas abrigadas para banho e uma boa oferta de restaurantes e meios de hospedagem, náo existindo evidências de lançamento de efluentes, nem estruturas antropogênicas que dificultem o uso. Já naquelas classificadas como de baixa qualidade recreacional, em geral, não existem zonas abrigadas para banho nem uma boa infraestrutura turística e de serviços. Com relação à capacidade de carga, as praias de Buraquinho, Vilas do Atlântico, Ipitanga, Itacimirim, Interlagos, Santo Antônio, Praia do Forte e Barra do Itariri apresentaram os menores valores de capacidades de carga (inferiores a 10.000 pessoas/ dia), considerando uma área ideal de $10 \mathrm{~m}^{2}$ usuário. Por outro lado, as praias com maior capacidade de carga, acima de 30.000 usuários/ dia, são as de Massarandupió, Sitio do Conde, Baixio e Costa Azul. As praias de Buraquinho, Barra do Jacuípe, Itacimirim, Praia do Forte, Imbassaí, Porto Sauípe, Massarandupió, Baixio, Barra do Itariri, Costa Azul e Mangue Seco apresentaram um limite ecológico mais restritivo para a capacidade de carga - estabelecido com base em características da cobertura vegetal, número de ecossistemas nas

@ - Autora correspondente: iracema@pesquisador.cnpq.br; silvair@ufba.br

1 - Universidade Federal da Bahia, Núcleo de Estudos Hidrogeológicos e do Meio Ambiente, Instituto de Geociências, Rua Caetano Moura, 123 - Federação - CEP40210-340 - Salvador, Bahia, Brasil.

2 - Universidade Federal da Bahia, Laboratório de Estudos Costeiros, CPGG, Instituto de Geociências, Rua Caetano Moura, 123 - Federação - CEP40210340 - Salvador, Bahia, Brasil.

3 - CIMA - Centro de Investigação Marinha e Ambiental, Universidade do Algarve, Edifício 7, Campus de Gambelas, 8005-139 Faro, Portugal.

4 - Instituto Federal de Educação, Ciência e Tecnologia Baiano, Campus Uruçuca. Rua Dr. João Nascimento S/No - Centro Uruçuca, Bahia, Brasil. 
proximidades da praia e densidade de construçôes fixas - e apenas a praia de Ipitanga apresentou um limite ecológico menos restritivo. Por fim, recomenda-se que os planos de gestão considerem de forma integrada as características recreacionais das praias, baseadas em parâmetros geoambientais e de infraestrutura, e a sua capacidade de carga, considerando os limites ecológicos e de acomodação destas praias.

Palavras-chave: qualidade recreacional, capacidade de carga, gerenciamento costeiro.

\section{ABSTRACT}

The Beaches of Bahia State Northern Coast are stretched over seven municipalities - Lauro de Freitas, Camaçari, Mata de São João, Entre Rios, Esplanada, Conde and Jandaira - approximately $200 \mathrm{~km}$ of coastline. The first three counties are closer to the Salvador Metropolitan Area (the State Capital). They include mostly urbanized and developed coastline segments, or sections being developed. The remaining counties present mostly pristine or uninhabited coastlines interrupted by occasional lightly-occupied areas. This study is aimed at evaluating the recreational quality and carrying capacity of these beaches, as well as its ecological constraints, providing scientific basis for local development planning. The recreational quality of these beaches was evaluated based on an approach involving indicators geo-environmental quality indicators (twenty) and available infrastructure (twelve). These indicators were identified and described during fieldwork (data collecting) undertaken between October 2010 and January 2011. The indicators were classified under three different levels of attractiveness: 1 for the lowest and 3 for the highest quality. The average area occupied per person (current scenario) was estimated for all beaches. The available area was measured and the carrying capacity was estimated based on "user perception" of "ideal occupation" for recreational activities. According to this approach, the beaches of Vilas do Atlântico, Buraquinho, Itacimirim, Praia do Forte, Imbassai and Subauma were classified as providing high recreational quality for their users. Conversely, the beaches of Busca Vida, Interlagos, Santo Antonio, Porto Sauipe, Massarandupió, Baixio and Sitio do Conde were classified as providing low recreational quality. In the first group, most beaches had naturally sheltered areas allowing safe water activities and a reasonable service infrastructure (restaurants and lodging). In addition, these beaches are apparently free of sewage and other man-made structures impacting recreational activities. Most beaches classified as providing low recreational quality offered no naturally protected areas for water activities or acceptable recreational infrastructure such as restaurants, snack bars, restrooms, lodging, etc. Regarding the carrying capacity analysis, the beaches of Buraquinho, Vilas do Atlantico, Ipitanga, Itacimirim, Interlagos, Santo Antonio, Praia do Forte and Barra do Itariri presented recreational area during low tide inferior to $100,000 \mathrm{~m} 2$, comprising the lowest values for carrying capacity $(<10,000$ peoplelday). The study assumes $10 \mathrm{~m} 2 /$ person (user) as the ideal carrying capacity scenario. The beaches classified as having superior carrying capacity are Massarandupio, Sitio do Conde, Baixio and Costa Azul, all superior to 300,000 m2 and carrying capacity beyond 30,000 users/ day. Buraquinho, Barra do Jacuipe, Itacimirim, Praia do Forte, Imbassai, Porto Sauipe, Massarandupió, Baixio, Barra do Itariri, Costa Azul and Mangue Seco beaches presented more restrictive carrying capacity limits - based on parameters such as plant cover, vulnerable ecosystems (mangroves, coral reefs, lagoons and dunes) near the coastline and density of man-made permanent structures within the coastal strip (50 meters from the shoreline). Only Ipitanga beach presented less restrictive ecological limits. The reaming beaches of Costa dos Coqueiros Region showed intermediate ecological limits. Therefore, most beaches included in the present study should have implemented tools for limiting their use based on their ability to accommodate users and provide them with recreational services. Although Ipitanga beach has presented less restrictive ecological limits, one must be aware of its low carrying capacity. Tourism and beach development planning must take into account geo-environmental and infrastructure constraints for they will affect recreational quality. Beaches providing superior recreational quality tend to attract more users but occupation must respect local ecological limits. Therefore, each beach must be dedicated to uses consistent with their capabilities and constraints.

Keywords: recreational quality, carrying capacity, local development planning.

\section{INTRODUÇÁO}

Em todo o mundo, as praias, com as suas diversas possibilidades de usos recreacionais, além do seu valor cênico e ecológico, constituem uma das principais motivaçóes vultuosos investimentos (Hall, 2001; Midaglia, 2001; Coriolano \& Silva, 2005; Ergin et al., 2006). Neste contexto, a avaliação da qualidade recreacional das praias através de indicadores geoambientais e das infraestruturas existentes, pode orientar os planos de gestão municipal, direcionando investimentos, de forma a garantir uma melhor utilização do litoral.

Por outro lado, o aumento do uso das praias como recurso recreacional criou a necessidade de se estabelecer a sua capacidade de carga, representando o número máximo de utilizadores que podem ser acomodados em uma determinada praia sem detrimento da sua qualidade recreacional (Archer \& Cooper, 2001; Williams \& Gill,
2001; Silva, 2002; Polette \& Raucci, 2003; Silva et al., 2006; Silva et al., 2009). Todavia, em tais trabalhos nota-se, em geral, uma preocupação e uma ênfase focadas muito mais em questóes sociais, com estudos baseados principalmente na capacidade de acomodação do que na sustentabilidade dos sistemas naturais. Uma outra questão a ser considerada é que, como a capacidade de carga tem como base a área útil de praia e esta é determinada num determinado momento para ser utilizada nos vários anos seguintes, por vezes os próprios investimentos (urbanos, infra-estruturais e outros) são guiados por esse valor de capacidade de carga. Todavia, como a praia é um sistema muito dinâmico, a área útil, ou faixa recreativa, é variável, sendo maior em uns anos e menor em outros, o que significa que a capacidade de carga também pode variar de maneira significativa.

Existe uma grande dificuldade em se estabelecer qual o limite de alteração dos sistemas naturais, induzida por 
atividades recreacionais, que se poderia considerar aceitável nos ecossistemas costeiros, uma vez que uma situação ideal, que deve ser usada como parâmetro de comparação, depende do comportamento e preferência dos usuários. No que tange à preferência, como apontam Haggett (2001) e Morgan (1999), a percepção dos visitantes sobre as qualidades ambiental e recreacional de uma praia pode ser influenciada por diversos fatores que, por sua vez, refletirão em diferentes preferências de usos. Quanto ao comportamento, Polette \& Raucci (2003), por exemplo, o consideram como um fator indutor de muitos problemas resultantes do uso recreacional das praias. Dessa maneira, o comportamento e a preferência dos usuários constituem fatores dinâmicos e diferenciados que podem variar amplamente com o tipo de usuário, do local e do período analisado, relativizando, assim, o estabelecimento de níveis de tolerância a eventuais alteraçóes nos ecossistemas costeiros. Por outro lado, embora no entendimento de Murphy (2001) e Williams \& Gill (2001) a ênfase deva ser dada para as condiçóes desejáveis para uma área e não para a carga de uso que ela pode tolerar, o estabelecimento de parâmetros de tolerância de uso, sejam eles ecológicos, de infraestrutura ou sociais, gera subsídios importantes para os planos de gestão.

A vocaçáo turística da costa do estado da Bahia tem sido comprovada através de vultosos investimentos turísticos implementados especialmente nas últimas duas décadas, gerando uma intensificação nos processos de urbanização e ocupação do litoral (Silva etal., 2008). O litoral norte do estado da Bahia, denominado Costa dos Coqueiros, compreende sete municípios: Lauro de Freitas, Camaçari, Mata de São João, Entre Rios, Esplanada, Conde e Jandaíra (Fig. 1). Ele abriga uma diversidade natural que inclui ecossistemas variados - dunas, lagos, recifes de corais, manguezais, brejos e praias - em aproximadamente $200 \mathrm{~km}$ de litoral. Essa diversidade ecológica, ao lado de uma facilidade de acesso, desperta a atração de visitantes e empresários, representando hoje um importante vetor de crescimento turístico do Estado da Bahia (Silva et al., 2008).

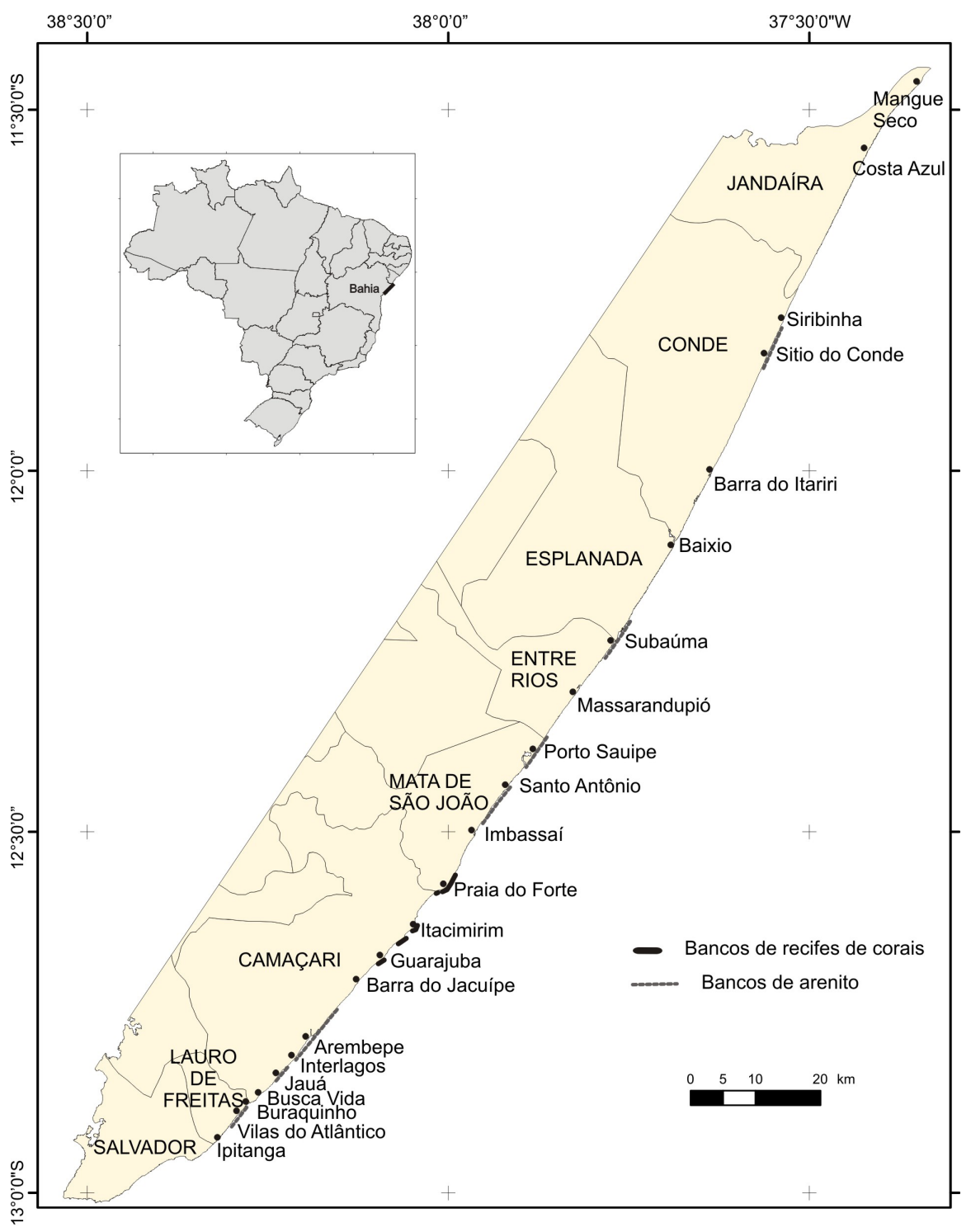

Figura 1. Limites municipais, praias estudadas e localização dos bancos de arenito e recifes de coral no Litoral Norte do Estado da Bahia.

Figure 1. County limits, studied beaches, sandstone banks and coral reefs on Bahia State Northern Coastline. 
A Costa dos Coqueiros apresenta micromarés semidiurnas sem desigualdades, com amplitude média de sizígia situandose em torno de 1,8 m (Dominguez et al., 1996). É delimitada na sua parte mais interna por depósitos semi-consolidados da Formação Barreiras, (Martin et al., 1980; Dominguez et al., 2009), de idade miocênica (Suguio \& Nogueira, 1999). Depósitos quaternários, representados fundamentalmente por terraços marinhos holocênicos e pleistocênicos são encontrados em quase toda a extensão da região costeira, bem como um cordão-duna ao longo de quase toda a linha de costa (Martin et al., 1980). Localmente, ocorrem também depósitos flúviolagunares e um extenso campo de dunas na região de Mangue Seco. Ainda ao longo da linha de costa ocorrem, pontualmente, bancos de recifes de corais e de arenitos de praia (Martin et al., 1980, Dominguez et al., 1996, Leâo \& Kikuchi, 1999). Todos esses locais formam conjuntos de inegável beleza cênica, o que justifica a forte atração para as atividades de turismo, recreação e lazer.

A ocupação da Costa dos Coqueiros não tem se dado de forma homogênea. O município de Lauro de Freitas, localizado na zona metropolitana de Salvador, apresenta um grau de urbanização elevado, com adensamento urbano concentrado principalmente no seu litoral. O município de Camaçari apresenta duas situaçóes diferenciadas em relaçáo à ocupação de seu litoral: praias que se inserem dentro de condomínios fechados - e que, muitas vezes, dificultam o acesso aos banhistas, ainda que esta seja uma prática inconstitucional - como Busca Vida e Interlagos, e praias que apresentam, na maior parte de sua extensão, acesso aberto ao público em geral, como Arembepe e Jauá. Ainda que nesses dois casos a urbanização seja intensa, a ocupaçâo do espaço se dá de forma diferenciada, no primeiro caso existindo um padrão de ocupação com um maior ordenamento do uso do espaço, o que não é observado no segundo, com uma ocupaçáo livre do espaço costeiro. A partir do município de Mata de São João para norte, o litoral apresenta apenas alguns pequenos núcleos urbanizados, como em Subaúma, Baixio e Sítio do Conde, e extensos trechos de praias desertas (Silva et al., 2008; Bittencourt et al., 2010). Para os próximos anos, contudo, estão previstos grandes investimentos para esta região, como, por exemplo, o que é noticiado pelo jornal "A Tarde" de 28/12/2008: cerca de 750 milhóes de reais para a construção de equipamentos turísticos e residenciais em Baixio, o que deverá impactar fortemente este trecho do litoral. Neste contexto, além do conhecimento já disponível no que tange à dinâmica sedimentar costeira da regiâo de estudo (e.g., Bittencourt et al., 2010; Dominguez et al., 1996), é de fundamental importância a realizaçâo de estudos referentes à qualidade recreacional e capacidade de carga das suas praias, bem como aos limites ecológicos da regiāo em apreço, que possam subsidiar os planos de uso e ocupação deste litoral. Nesse sentido, o presente trabalho teve como objetivo a realização de tais estudos nas praias que apresentam as maiores demandas por usuários ao longo da Costa dos Coqueiros.

\section{MATERIAL E MÉTODOS}

\subsection{Avaliaçáo da qualidade recreacional das praias}

A qualidade recreacional das praias da Costa dos Coqueiros foi avaliada a partir da análise de indicadores de qualidade geoambiental e de infraestrutura, extraídos de Leatherman (1997), Silva et al., (2003) e Araújo \& Costa (2008). Para tanto, foram utilizados, para aplicação no presente trabalho, os indicadores aqui considerados como mais significativos para o alcance dos objetivos propostos, sendo 20 indicadores de qualidade geoambiental (Tabela 1) e 12 de infraestrutura para uso recreacional (Tabela 2), avaliados a partir de caminhamentos feitos ao longo das praias estudadas no período entre outubro de 2010 e janeiro de 2011 (primaveral verão), durante finais de semana e feriados, nos horários de maior freqüência de banhistas (12 às $15 \mathrm{~h}$ ).

Quanto aos critérios propostos pelos autores acima citados para a avaliação desses indicadores, no presente trabalho foram feitas poucas modificações, em função das características locais. Neste estudo, devido à grande variabilidade de preferências dos usuários em diferentes locais, todos os indicadores foram considerados com o mesmo peso na determinação da qualidade das praias.

Os indicadores foram classificados em diferentes graus de atratividade, sendo para cada um deles atribuídos valores de 1 a 3 (1- baixa qualidade; 2- qualidade intermediária; 3- alta qualidade). Osindicadores 7 e 19 (Tabela 1) foram classificados em apenas duas categorias. A qualidade recreacional de cada praia foi expressa pela média aritmética dos valores atribuídos a cada um dos indicadores geoambientais e de infraestrutura. Esta média aritmética, conforme indicado no Tabela 6, foi feita dividindo-se o somatório dos valores encontrados para cada praia por 32, que representa o número de indicadores considerados na análise.

Como, em geral, as praias apresentaram significativas variações espaciais, tanto ambientais como de ocupação e infraestrutura, foram consideradas as características representativas dos trechos de maior demanda para atividades recreacionais, tendo sido padronizada uma extensão de $1 \mathrm{~km}$ dentro da área de maior uso destas praias, segundo observação local.

\subsubsection{Indicadores da Qualidade Geoambiental (Tabela 1)}

$\mathrm{Na}$ avaliação de áreas para banho, no que tange ao grau de exposiçâo às ondas (indicador 1), foram consideradas como praias expostas aquelas com franca atuação das ondas; como praias parcialmente abrigadas, aquelas onde bancos de arenito de praia ou de recifes de corais criam localmente uma pequena região protegida; e, como praias abrigadas, aquelas onde estas estruturas protegem a costa da ação das ondas em pelo menos $50 \%$ da extensão da praia.

Com relaçãoàvulnerabilidadeaprocessoserosivos(indicador 9), foram consideradas como praias com vulnerabilidade baixa a erosão aquelas que não apresentam evidências de erosão; com vulnerabilidade alta, as praias com significativas evidências de erosão (escarpa erosiva nos terraços marinhos holocênicos ou no cordáo-duna, coqueiros caídos, coqueiros com raízes expostas e existência de estruturas de proteção) na maior parte de sua extensão e, com vulnerabilidade média, as praias com algumas evidências pontuais desses indicadores de erosão, conforme critérios utilizados em Silva et al., (2007).

As estruturas antropogênicas (indicador (normalmente estruturas de proteção contra erosão, como 
muros de contenção e enrocamentos) ou naturais (indicador 11) (normalmente bancos de arenito) que dificultam o uso da praia foram consideradas como poucas quando ocupam uma extensão inferior a $30 \%$ do comprimento da praia e, muitas, quando ocupam uma extensão superior a esta.

$\mathrm{Na}$ avaliação da tipologia do litoral (indicador 12), foi considerada como muito urbanizada a praia com mais de $70 \%$ de construçóes fixas em uma faixa costeira de $50 \mathrm{~m}$ a partir da linha de preamar máxima; pouco urbanizada, com 30 a $70 \%$ de construçôes e, abaixo de 30\%, foi considerada como muito pouco urbanizada, seguindo critérios de percentuais utilizados em Silva et al., (2008).

Foram consideradas como evidências de descarga de esgoto (indicador 19) a) a constatação visual de esgoto na praia, b) as informaçóes de moradores ou comerciantes locais sobre esse tipo de ocorrência e, c) quando da presença de estruturas (como fossas) que indiquem a descarga eventual de esgotos, já que não existem análises disponíveis acerca da balneabilidade destas praias. Com relaçáo às presenças de óleo ou piche, algas e água viva (respectivamente, indicadores 16,18 e 20), foram consideradas como freqüentes quando de ocorrências superiores a dez itens por quilômetro linear de praia e, com pouca quantidade, quando inferiores a este valor.

\subsubsection{Indicadores da Qualidade de Infraestrutura (Tabela 2)}

Para os indicadores referentes à presença de sanitários e banheiros (indicador 1), lanchonete, bares e restaurantes (indicador 2), meios de hospedagem (indicador 3), telefone público (indicador 5), facilidades para recreação (indicador 6) e animais domésticos (indicador 12), foram considerados como poucos quando constatados menos de três ocorrências ao longo do quilômetro de praia e zona costeira adjacente (até $50 \mathrm{~m}$ a partir da zona de pós-praia) analisados. No caso da presença de estacionamento (indicador 4), foi considerada a disponibilidade de vagas para veículos levando em conta a demanda de cada praia, a partir da estimativa visual das condiçóes de estacionamento durante o verão. $\mathrm{O}$ transporte público (indicador 7) foi considerado restrito quando está disponível apenas em um ponto específico dentro do trecho analisado.

\subsection{Avaliação da capacidade de carga}

Os mesmos trechos de $1 \mathrm{~km}$ selecionados para a avaliação da qualidade recreacional das praias estudadas no presente trabalho foram utilizados para a avaliação da capacidade de carga das mesmas. Esses trechos foram segmentados em células de $50 \mathrm{~m}$ de comprimento (compreendendo as zonas do pós-praia e da face da praia) e medidas, em cada uma delas, as suas larguras inicial e final. A partir desses valores foi calculada a área de cada célula. Em cada célula foi então realizada a contagem do número de pessoas. Essas contagens foram sempre realizadas no horário de 11:00 às 16:00 h, considerado como de maior freqüência pela observação do local, o que foi confirmado a partir de fotografias. Para isso, considerou-se a Praia do Forte como referência, sendo fotografada entre 8:00 e 18:00 horas, a cada hora, a fim de possibilitar a identificação do fluxo de usuários durante o dia. Buscou-se sempre realizar a contagem, bem como as medidas de cada célula de praia, durante finais de semana e feriados, quando havia um maior fluxo de freqüentadores e em horários durante ou próximos à baixa-mar. Foi então calculada a relação entre a área de cada célula e o número de frequentadores, encontrando, assim, a área, em metros quadrados, de praia disponível para cada usuário. A contagem dos frequentadores foi realizada nas zonas denominadas de ativa (face da praia, local próximo ao mar e usado, por exemplo, para a prática de jogos como frescobol) e de solarium (pós-praia, local onde as pessoas tomam banho de sol e usam cadeiras e sombreiros) (Pollete \& Raucci, 2003). Durante esta contagem, nas praias de Arembepe, Praia do Forte e Baixio () - representativas, respectivamente, de condição de uso intenso, intermediário e baixo - foram realizadas, de maneira aleatória, 40 entrevistas intencionais em cada uma delas, sendo os usuários questionados quanto ao tamanho da área de praia que consideram ideal para o seu uso, indicado a partir de fotografias tiradas previamente nestas praias, representando três situações diferentes de ocupação da praia: com 1 a 4,4 a 8 e 8 a $12 \mathrm{~m}^{2}$ disponíveis por usuário. Assim, para cada praia estudada foi estimada a) a área média utilizada por usuário (nível de uso atual), b) a área disponível para acomodação dos usuários e c) a capacidade de carga a partir da percepção predominante entre os usuários das praias de Arembepe, Praia do Forte e Baixio quanto ao tamanho da área de praia ideal que consideram para seu uso.

\subsection{Avaliaçáo do limite ecológico da capacidade de carga (Tabela 3)}

Segundo Silva (2002), a capacidade de carga ecológica pode ser definida como o limite máximo de uso recreativo que uma determinada área ou ecossistema pode suportar sem que ocorra um declínio irreversível de seus valores ecológicos, ou seja, sem que o limite de resiliência seja ultrapassado. O limite de uso, estabelecido geralmente em planos de gestão, normalmente variam de acordo com os parâmetros de impacto avaliados, definidos principalmente em função dos objetivos de gestão de cada área, devendo-se considerar sempre os limites de resiliência dos sistemas naturais.

Como consideram Silva et al., (2008), nos locais de maior demanda turística a vegetação original na beira-mar (no pós-praia e zona costeira adjacente) é, geralmente, retirada, sendo substituída por uma vegetação exógena, ou cede lugar para a construção de restaurantes, casas, pousadas, hotéis, etc., sendo este um importante parâmetro de avaliação da alteração da paisagem costeira (Cin \& Simeoni, 1994). Essas construçóes alteram a paisagem natural, dificultam o acesso à praia e interferem na dinâmica costeira. Além disso, em praias com grande demanda recreacional, o pisoteio pode danificar a vegetação, especialmente em praias com dunas, podendo, inclusive amplificar localmente as taxas de recuo da linha de costa devido à movimentaçáo de dunas anteriormente estabilizadas pela vegetação.

A estimativa do limite ecológico da capacidade de carga das praias estudadas neste trabalho foi baseada na avaliação dos seguintes indicadores: a) características da cobertura vegetal, b) número de ecossistemas sensíveis (manguezais, recifes de coral, lagoas e dunas) nas proximidades da praia e 
Tabela 1. Indicadores de Qualidade Geoambiental utilizados para as praias do Litoral Norte da Bahia [modificado de Leatherman (1997), Silva et al., (2003) e Araújo \& Costa (2008)].

Table 1. Geo-environmental Quality Indicators applied to Bahia State Northern Beaches [modified from Leatherman (1997), Silva et al., (2003) and Araújo \& Costa (2008)].

\begin{tabular}{|c|c|c|c|}
\hline \multirow[b]{2}{*}{ INDICADORES AVALIADOS } & \multicolumn{3}{|c|}{ GRAU DE ATRATIVIDADE } \\
\hline & BAIXO (1) & MÉDIO (2) & ALTO (3) \\
\hline 1.Áreas para banho ${ }^{3}$ & Praia exposta & Parcialmente abrigada & Praia abrigada \\
\hline $\begin{array}{l}\text { 2.Grandes ondas }(>1 \mathrm{~m}) \text { quebrando direta- } \\
\text { mente na face da praia }{ }^{1,2,3}\end{array}$ & Frequentes & Ocasionalmente presentes & Ausentes \\
\hline 3.Correntes de retorno ${ }^{1,3}$ & Frequentes & Ocasionalmente presentes & Ausentes \\
\hline 4.Declividade face da praia ${ }^{1,2,3}$ & Muito inclinada $\left(>10^{\circ}\right)$ & $\begin{array}{l}\text { Inclinação moderada } \\
\left(5^{\circ}-10^{\circ}\right)\end{array}$ & Pouco inclinada $\left(<5^{\circ}\right)$ \\
\hline 5.Material componente da face da praia ${ }^{1,2,3}$ & Rocha ou argila & $\begin{array}{l}\text { Seixos, grânulos, areia } \\
\text { grossa }\end{array}$ & Areia fina ou média \\
\hline 6.Coloraçấo do sedimento praial ${ }^{1,2,3}$ & Escura & Bege & Clara (branco) \\
\hline 7.Claridade da água (verão) ${ }^{1,2,3}$ & Alta turbidez & & Baixa turbidez \\
\hline 8.Largura da face da praia na maré baixa ${ }^{1,2,3}$ & Estreita $(<10 \mathrm{~m})$ & Intermediária $(10-30 \mathrm{~m})$ & Larga $(>30 \mathrm{~m})$ \\
\hline 9.Vulnerabilidade à erosáo costeira ${ }^{1,3}$ & Alta & Média & Baixa \\
\hline $\begin{array}{l}\text { 1. 10.Estruturas antropogênicas que } \\
\text { dificultem a circulação do usuário na } \\
\text { praia }^{1,2,3}\end{array}$ & Muitas & Poucas & Ausentes \\
\hline $\begin{array}{l}\text { 11.Estruturas naturais que dificultem o uso } \\
\text { da praia (ex. bancos de arenitos de praia) })^{1,2}\end{array}$ & Muitas & Poucas & Ausentes \\
\hline $\begin{array}{l}\text { 2. 12.Tipologia do litoral de acordo com o } \\
\text { grau de ocupaçáo urbana }{ }^{1,3}\end{array}$ & Muito urbanizado & Pouco urbanizado & $\begin{array}{l}\text { Muito pouco urba- } \\
\text { nizado }\end{array}$ \\
\hline 13.Construçôes fixas ${ }^{1,3}$ & No pós-praia & $\begin{array}{l}\text { Na zona cost. adjacente ao } \\
\text { pós-praia }\end{array}$ & Ausentes \\
\hline $\begin{array}{l}\text { 3. 14.Ecossistemas sensíveis associados à } \\
\text { praia (recifes de corais, dunas, mangue- } \\
\text { zais etc) })^{1,3}\end{array}$ & Ausentes & Presença de um ecossistema & $\begin{array}{l}\text { Presença de pelo me- } \\
\text { nos dois ecossistemas }\end{array}$ \\
\hline 15.Cobertura vegetal no pós-praia ${ }^{1,3}$ & $\begin{array}{l}\text { Sem vegetação em mais de } \\
50 \% \text { da extensão }\end{array}$ & $\begin{array}{l}\text { Com vegetação não nativa } \\
\text { em mais de } 50 \% \text { da ex- } \\
\text { tensão }\end{array}$ & $\begin{array}{l}\text { Com vegetação nativa } \\
\text { em mais de } 50 \% \text { da } \\
\text { extensáo }\end{array}$ \\
\hline 16.Óleo ou piche na praia ou na água ${ }^{1,3}$ & Frequente & Pouca quantidade & Ausente \\
\hline $\begin{array}{l}\text { 17.Acumulaçáo de lixo marinho (itens por } \\
\mathrm{km} \text { linear de praia) }{ }^{1,2,3}\end{array}$ & $>100$ unidades & $100-30$ unidades & $<30$ unidades \\
\hline 18.Algas na areia ou na coluna d'água ${ }^{1,3}$ & Frequentes & Pouca quantidade & Ausente \\
\hline $\begin{array}{l}\text { 19.Descarga de esgoto } \\
\text { (na praia ou no mar) })^{1,2,3}\end{array}$ & Presente & & Ausente \\
\hline 20.Água viva ${ }^{1,3}$ & Frequente & Pouca quantidade & Ausente \\
\hline
\end{tabular}

Indicadores utilizados por: ${ }^{1}$ Leatherman (1997), ${ }^{2}$ Silva et al. (2003) e ${ }^{3}$ Araújo e Costa (2008). 
Tabela 2. Indicadores de Qualidade de Infraestrutura utilizados para as praias do Litoral Norte da Bahia [modificado de Leatherman (1997), Silva et al., (2003) e Araújo \& Costa (2008)].

Table 2. Infrastructure Quality Indicators applied to Bahia State Northern Beaches [modified from Leatherman (1997), Silva et al., (2003) and Araújo or Costa (2008)].

\begin{tabular}{|c|c|c|c|}
\hline \multirow{2}{*}{ INDICADORES AVALIADOS } & \multicolumn{3}{|c|}{ GRAU DE ATRATIVIDADE } \\
\hline & BAIXO (1) & MÉDIO (2) & ALTO (3) \\
\hline 1.Sanitários e banheiros em boas condiçôes ${ }^{1,2,3}$ & Ausentes & Poucos & $\begin{array}{l}\text { Quantidade Ade- } \\
\text { quada }\end{array}$ \\
\hline 2.Lanchonetes, bares e restaurantes ${ }^{1,2,3}$ & Ausentes & Poucos & $\begin{array}{l}\text { Quantidade Ade- } \\
\text { quada }\end{array}$ \\
\hline 3.Meios de hospedagem ${ }^{3}$ & Ausentes & Poucos & $\begin{array}{l}\text { Quantidade Ade- } \\
\text { quada }\end{array}$ \\
\hline 4.Estacionamento ${ }^{3}$ & Ausente & Poucos & $\begin{array}{l}\text { Quantidade Ade- } \\
\text { quada }\end{array}$ \\
\hline 5.Telefone público a pouca distância da praia ${ }^{3}$ & Ausente & Poucos & $\begin{array}{l}\text { Quantidade Ade- } \\
\text { quada }\end{array}$ \\
\hline $\begin{array}{l}\text { 6. Facilidades para recreação (quadras, aluguel } \\
\text { de caiaques etc) }{ }^{1,2,3}\end{array}$ & Ausentes & Poucas & $\begin{array}{l}\text { Quantidade Ade- } \\
\text { quada }\end{array}$ \\
\hline 7.Transporte público ${ }^{1,2,3}$ & Ausente & Restrito & $\begin{array}{l}\text { Disponibilidade } \\
\text { Adequada }\end{array}$ \\
\hline 8.Acesso a praia ${ }^{1,2,3}$ & Inadequado & $\begin{array}{l}\text { Adequado (não pavi- } \\
\text { mentado) }\end{array}$ & $\begin{array}{l}\text { Adequado (pavimen- } \\
\text { tado) }\end{array}$ \\
\hline 9.Diferença de nível até a praia ${ }^{3}$ & $\begin{array}{l}\text { Desnível, com escada ou } \\
\text { rampa inadequadas }\end{array}$ & $\begin{array}{l}\text { Desnível, com escada } \\
\text { ou rampa adequadas }\end{array}$ & Sem desnível \\
\hline 10.Ciclovia ${ }^{3}$ & Não disponível & Inadequada & Adequada \\
\hline 11.Salva-vidas ${ }^{1,3}$ & Ausentes & Poucos & $\begin{array}{l}\text { Quantidade Ade- } \\
\text { quada }\end{array}$ \\
\hline 12.Animais domésticos ${ }^{1,3}$ & Frequentes & Pouco frequentes & Ausentes \\
\hline
\end{tabular}

Indicadores utilizados por: ${ }^{1}$ Leatherman (1997), ${ }^{2}$ Silva et al. (2003) e ${ }^{3}$ Araújo e Costa (2008).

Tabela 3. Indicadores utilizados para a avaliação do limite ecológico da capacidade de carga das praias do Litoral Norte da Bahia.

Table 3. Indicators used to assess carrying capacity ecological limits for Bahia State Northern Beaches.

\begin{tabular}{|c|c|c|c|}
\hline \multirow[t]{2}{*}{ INDICADORES AVALIADOS } & \multicolumn{3}{|c|}{ ÍNDICE } \\
\hline & 1 & 2 & 3 \\
\hline COBERTURA VEGETAL & $\begin{array}{c}\text { Com vegetaçáo nativa em } \\
\text { mais de } 50 \% \text { da extensão } \\
\text { da praia }\end{array}$ & $\begin{array}{c}\text { Com plantação de coqueiros } \\
\text { ou outros tipos de culturas } \\
\text { não nativas }(>50 \%)\end{array}$ & $\begin{array}{c}\text { Sem vegetação em mais } \\
\text { de } 50 \% \text { da extensão da } \\
\text { praia }\end{array}$ \\
\hline CONSTRUÇÓES FIXAS & $\begin{array}{l}\text { Em menos de } 30 \% \text { da } \\
\text { extensão da praia }\end{array}$ & $\begin{array}{l}\text { Entre } 30 \text { e } 70 \% \text { da extensão } \\
\text { da praia }\end{array}$ & $\begin{array}{l}\text { Em mais de } 70 \% \text { da } \\
\text { extensão da praia }\end{array}$ \\
\hline $\begin{array}{l}\text { ECOSSISTEMAS SENSÍVEIS AS- } \\
\text { SOCIADOS À PRAIA }\end{array}$ & Pelo menos dois tipos & Apenas um tipo & Ausência \\
\hline
\end{tabular}


c) densidade de construçóes fixas numa faixa costeira de 50 $\mathrm{m}$ de largura a partir da linha de costa. Para cada um destes parâmetros foi associado um valor de 1 a 3 . O somatório dos valores encontrados foi usado como indicativo de um limite ecológico mais restritivo (valores entre 3 e 5), limite intermediário (valores entre 6 e 7) e um limite ecológico menos restritivo para capacidade de carga (valores entre 8 e 9). Deve-se, contudo, salientar o caráter simplista e experimental desta análise, com um número reduzido de indicadores, que deverá ser ampliada em estudos posteriores.

\section{RESULTADOS E DISCUSSÓES}

\subsection{Qualidade Recreacional}

As tabelas 4 e 5 mostram, respectivamente, os valores atribuídos, por praia, a cada um dos indicadores avaliados referentes às qualidades geoambiental e de infraestrutura, bem como os índices resultantes de qualidade geoambiental e de infraestrutura, de cada praia, representados pelo somatório destes valores. A variação desses índices ao longo do litoral, bem como o valor médio dos mesmos, estáo expressos na figura 2. Por esta figura constata-se que as curvas de variação destes índices apresentam, de uma maneira geral, um notável paralelismo entre as praias de Ipitanga (A) e Baixio (R), o que inexiste daí até Mangue Seco (X). Em relação ao primeiro trecho costeiro, uma região que tem recebido historicamente investimentos em infraestrutura ao longo da linha de costa (Silva et al., 2008), é razoável esperar que, quanto melhores as condiçóes geoambientais das praias, tanto maior deve ser a demanda por elas para recreação e lazer, o que, consequentemente, também é esperado ser acompanhado por uma maior oferta de infraestrutura, que, no entanto, pode vir a comprometer a qualidade geoambiental destas praias. Quanto ao segundo trecho costeiro, trata-se de uma área muito pouco antropizada, com características rurais (Alva, 2003; Silva et al., 2008), que não tem sido ainda alvo de significativos investimentos em infraestrutura visando atrair usuários na busca de recreação e lazer (Silva et al., 2008).

A tabela 6 mostra a qualidade recreacional das praias do Litoral Norte do Estado da Bahia, em função dos índices das qualidades geoambiental e de infraestrutura, expressos nas tabelas 4 e 5 , respectivamente. Pela tabela 6 , constata-se que as praias de Vilas do Atlântico, Buraquinho, Itacimirim, Praia do Forte, Imbassaí e Subaúma foram classificadas como de alta qualidade recreacional. Na maior parte destas praias (Tabelas 4 e 5) existem zonas abrigadas para banho e uma boa oferta de restaurantes e meios de hospedagem, não existindo evidências de esgoto (não existem dados de balneabilidade para estas praias), nem estruturas antropogênicas que dificultem o uso (Fig. 3 e 4). Já as praias de Busca Vida, Interlagos, Santo Antônio, Porto Sauípe, Massarandupió, Baixio e Sitio do Conde (Tabelas 4 e 5) apresentaram uma qualidade recreacional baixa, principalmente devido à ausência de zonas abrigadas para banho e a falta de infraestrutura recreacional, como a presença de restaurantes, lanchonetes, sanitários, meios de hospedagem e facilidades para recreação (Fig. 5 e 6).

Deve-se salientar, contudo, que a oferta de equipamentos como bares e restaurantes a beira mar, apesar de aumentarem a qualidade de infraestrutura das praias, muitas vezes interferem na dinâmica costeira local, acelerando, por exemplo, processos erosivos. Muitos destes empreendimentos não são autorizados pelas prefeituras locais e funcionam de forma irregular.

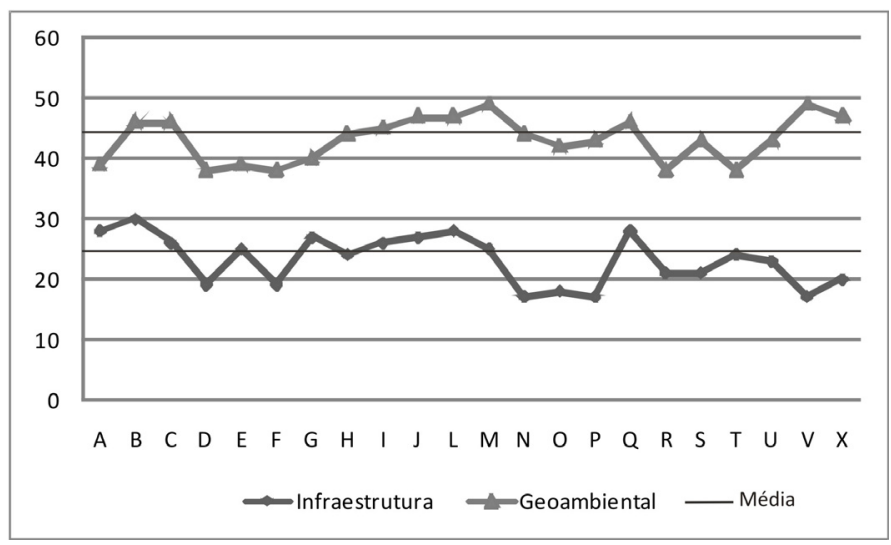

Figura 2. Índices das qualidades geoambiental e de infraestrutura para as praias do Litoral Norte do Estado da Bahia (ver tabelas 4 e 5): A-Ipitanga; B-Vilas do Atlântico; C-Buraquinho; D-Busca Vida; E-Jauá; F-Interlagos; G-Arembepe; H-Barra do Jacuípe; I-Guarajuba; J-Itacimirim; L-Praia do Forte; M-Imbassaí; N-Santo Antônio; O-Porto Sauípe; P- Massarandupió; Q-Subaúma; R-Baixio; S-Barra do Itariri; T-Sítio do Conde; U-Siribinha; V-Costa Azul; X-Mangue Seco.

Figure 2. Geo-environmental and infrastructure Indicators for Bahia State Northern Coast Beaches (see Tables 4 and 5): A-Ipitanga; B-Vilas do Atlântico; C-Buraquinho; D-Busca Vida; E-Jauá; F-Interlagos; G-Arembepe; H-Barra do Jacuipe; I-Guarajuba; J-Itacimirim; L-Praia do Forte; M-Imbassai; N-Santo Antônio; O-Porto Sauipe; PMassarandupió; Q-Subaúma; R-Baixio; S-Barra do Itariri; T-Sítio do Conde; U-Siribinha; V-Costa Azul; X-Mangue Seco.

\subsection{Avaliaçáo da Capacidade de Carga}

O nível de uso ideal das praias, segundo a percepçáo dos freqüentadores das praias de Baixio, Arembepe e Praia do Forte - na sua maioria originários da própria localidade ou de cidades vizinhas, no caso das duas primeiras, e de outras regióes ou estrangeiros, no caso de Praia do Forte, conforme indicado durante as entrevistas - foi de 8 a 12 $\mathrm{m}^{2}$ de área por usuário, tendo sido então utilizado para o cálculo da capacidade de carga ideal o valor médio de 10 $\mathrm{m}^{2}$ por usuário. Não se deve desconsiderar, contudo, que foi feita uma aproximação, extrapolando a preferência dos usuários entrevistados na amostragem para um padrão geral representativo das praias analisadas no presente estudo.

O fluxo de usuários durante o período das 8 às 18:00 horas na Praia do Forte (fotos tiradas no dia 9 de janeiro de 2011) aponta para uma maior concentração entre 12 e 15 horas (Fig. 7), o que foi também extrapolado para todas as demais praias do presente estudo. 


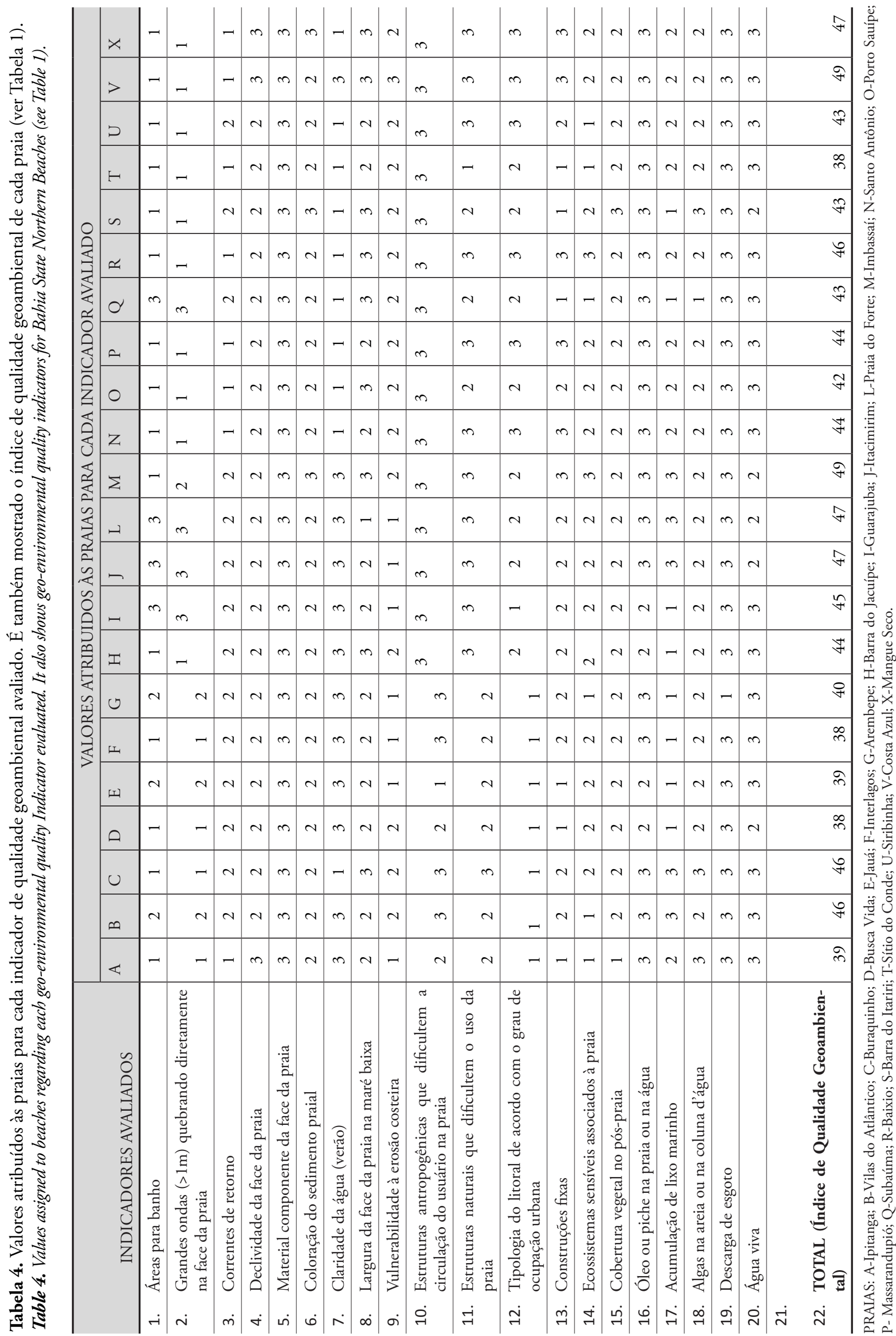


Tabela 5. Valores atribuídos às praias para cada indicador de qualidade de infraestrutura avaliado. É também mostrado o índice de qualidade de infraestrutura de cada praia (ver Tabela 2).

Table 5. Values assigned to beaches regarding each infrastructure quality indicator evaluated. It also shows infrastructure quality indicators for Bahia State Northern Beaches (see Table 2).

\begin{tabular}{|c|c|c|c|c|c|c|c|c|c|c|c|c|c|c|c|c|c|c|c|c|c|c|}
\hline \multirow[b]{2}{*}{ INDICADORES AVALIADOS } & \multicolumn{22}{|c|}{ VALORES ATRIBUÍDOS ÀS PRAIAS PARA CADA INDICADOR ALAVIADO } \\
\hline & A & $\mathrm{B}$ & $\mathrm{C}$ & $\mathrm{D}$ & $\mathrm{E}$ & $\mathrm{F}$ & G & $\mathrm{H}$ & I & $\mathrm{J}$ & $\mathrm{L}$ & M & $\mathrm{N}$ & $\mathrm{O}$ & $\mathrm{P}$ & Q & $\mathrm{R}$ & $S$ & $\mathrm{~T}$ & $\mathrm{U}$ & $\mathrm{V}$ & $\mathrm{X}$ \\
\hline - $\quad$ Sanitários e banheiros & 2 & 2 & 2 & 1 & 1 & 1 & 2 & 2 & 2 & 2 & 2 & 2 & 1 & 1 & 1 & 2 & 1 & 2 & 1 & 2 & 1 & 1 \\
\hline $\begin{array}{l}\text { - Lanchonetes, bares e restau- } \\
\text { rantes }\end{array}$ & 3 & 2 & 3 & 1 & 3 & 1 & 3 & 2 & 3 & 3 & 3 & 2 & 1 & 1 & 1 & 3 & 2 & 2 & 2 & 2 & 2 & 2 \\
\hline - $\quad$ Meios de hospedagem & 3 & 3 & 2 & 2 & 3 & 1 & 3 & 2 & 3 & 3 & 3 & 3 & 1 & 1 & 1 & 3 & 2 & 2 & 2 & 2 & 1 & 3 \\
\hline - Estacionamento & 2 & 2 & 2 & 2 & 2 & 2 & 2 & 2 & 2 & 2 & 2 & 2 & 1 & 1 & 1 & 3 & 2 & 2 & 2 & 2 & 1 & 1 \\
\hline $\begin{array}{l}\text { - Telefone público a pouca distân- } \\
\text { cia da praia }\end{array}$ & 2 & 2 & 1 & 1 & 2 & 1 & 2 & 2 & 1 & 1 & 2 & 1 & 1 & 1 & 1 & 2 & 1 & 2 & 2 & 2 & 1 & 1 \\
\hline - $\quad$ Facilidades para recreação & 2 & 2 & 1 & 2 & 2 & 2 & 1 & 2 & 1 & 1 & 2 & 2 & 1 & 1 & 1 & 1 & 1 & 1 & 1 & 1 & 1 & 1 \\
\hline - $\quad$ Transporte público & 3 & 3 & 2 & 2 & 3 & 2 & 3 & 2 & 2 & 2 & 3 & 2 & 2 & 2 & 2 & 3 & 2 & 1 & 2 & 2 & 1 & 2 \\
\hline - Acesso a praia & 3 & 3 & 3 & 3 & 3 & 3 & 3 & 3 & 3 & 3 & 3 & 2 & 1 & 1 & 1 & 3 & 2 & 2 & 3 & 3 & 1 & 1 \\
\hline - Diferença de nível até a praia & 3 & 3 & 3 & 1 & 1 & 2 & 2 & 2 & 1 & 3 & 3 & 3 & 3 & 3 & 3 & 2 & 3 & 3 & 3 & 3 & 3 & 3 \\
\hline - Ciclovia & 1 & 3 & 3 & 1 & 1 & 1 & 1 & 1 & 3 & 1 & 1 & 1 & 1 & 1 & 1 & 1 & 1 & 1 & 2 & 1 & 1 & 1 \\
\hline - $\quad$ Salva-vidas & 2 & 3 & 2 & 1 & 2 & 1 & 3 & 2 & 3 & 3 & 3 & 3 & 1 & 2 & 1 & 3 & 2 & 1 & 1 & 1 & 1 & 1 \\
\hline - $\quad$ Animais domésticos & 2 & 2 & 2 & 2 & 2 & 2 & 2 & 2 & 2 & 3 & 3 & 2 & 3 & 3 & 3 & 2 & 2 & 2 & 2 & 2 & 3 & 3 \\
\hline $\begin{array}{l}\text { TOTAL (Índice de Qualidade de } \\
\text { Infraestrutura) }\end{array}$ & 28 & 30 & 26 & 19 & 25 & 19 & 27 & 24 & 26 & 27 & 28 & 25 & 17 & 18 & 18 & 28 & 19 & 21 & 24 & 23 & 17 & 20 \\
\hline
\end{tabular}

PRAIAS: A-Ipitanga; B-Vilas do Atlântico; C-Buraquinho; D-Busca Vida; E-Jauá; F-Interlagos; G-Arembepe; H-Barra do Jacuípe; I-Guarajuba; J-Itacimirim; L-Praia do Forte; M-Imbassaí; N-Santo Antônio; O-Porto Sauípe; P- Massarandupió; Q-Subaúma; R-Baixio; S-Barra do Itariri; T-Sítio do Conde; U-Siribinha; V-Costa Azul; X-Mangue Seco.

Tabela 6. Qualidade Recreacional das praias do Litoral Norte da Bahia, em função dos índices das qualidades geoambiental e de infraestrutura (ver tabelas 4 e 5).

Table 6. Recreational Quality for Bahia State Northern Beaches, according to geo-environmental and infrastructure quality indicators (see Tables 4 and 5).

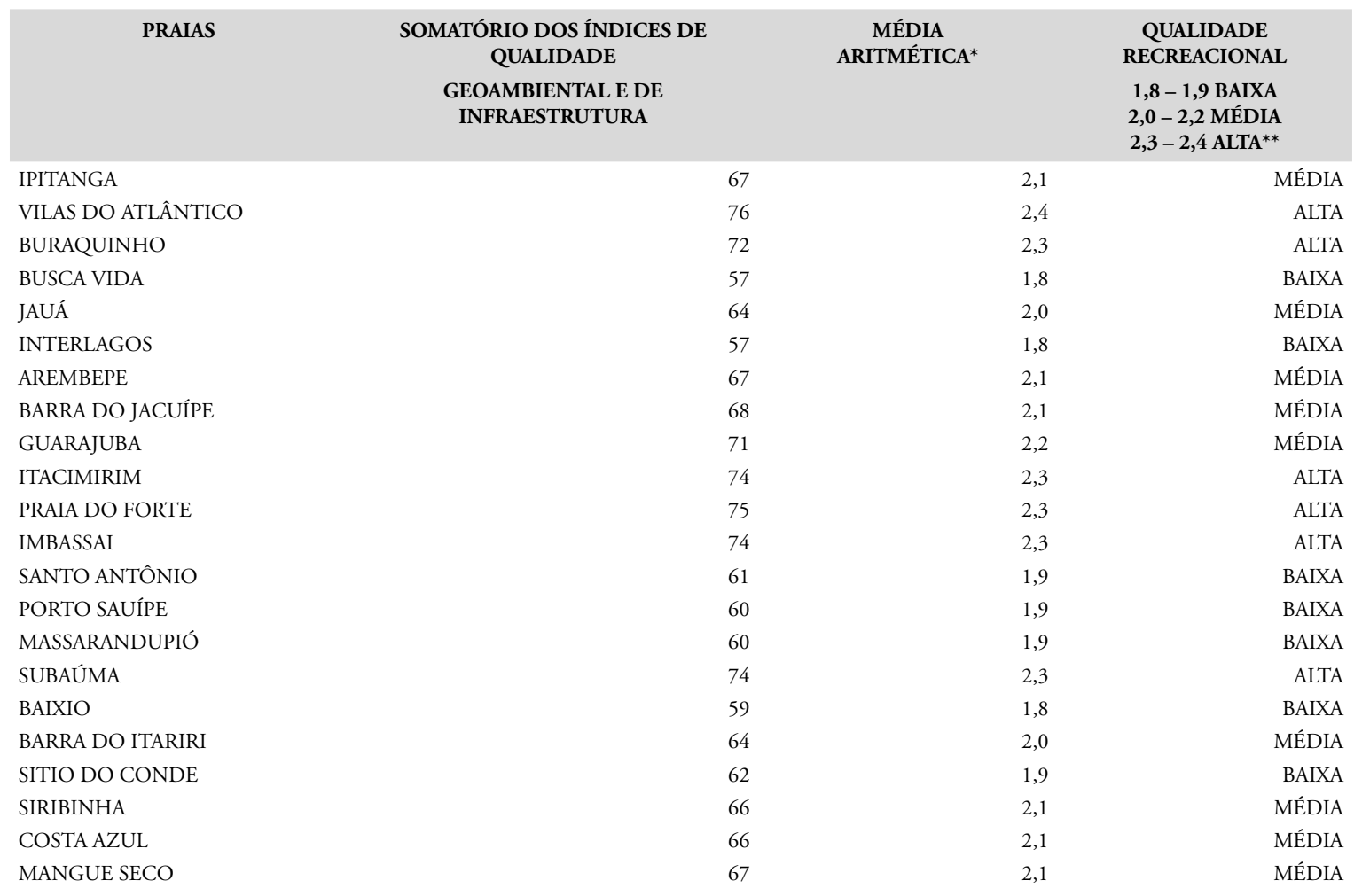

*somatório dos índices/ 32 (número total de indicadores)

** 1,8 representa o valor mínimo encontrado e 2,4 o valor máximo. 


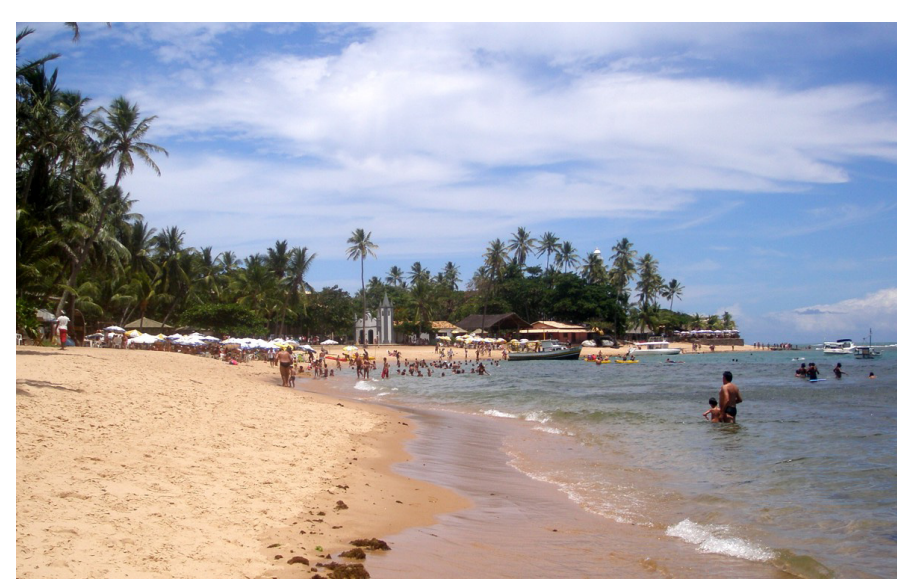

Figura 3. Praia do Forte - classificada como de alta qualidade recreacional.

Figure 3. Praia do Forte Beach - classified as "high recreational quality".

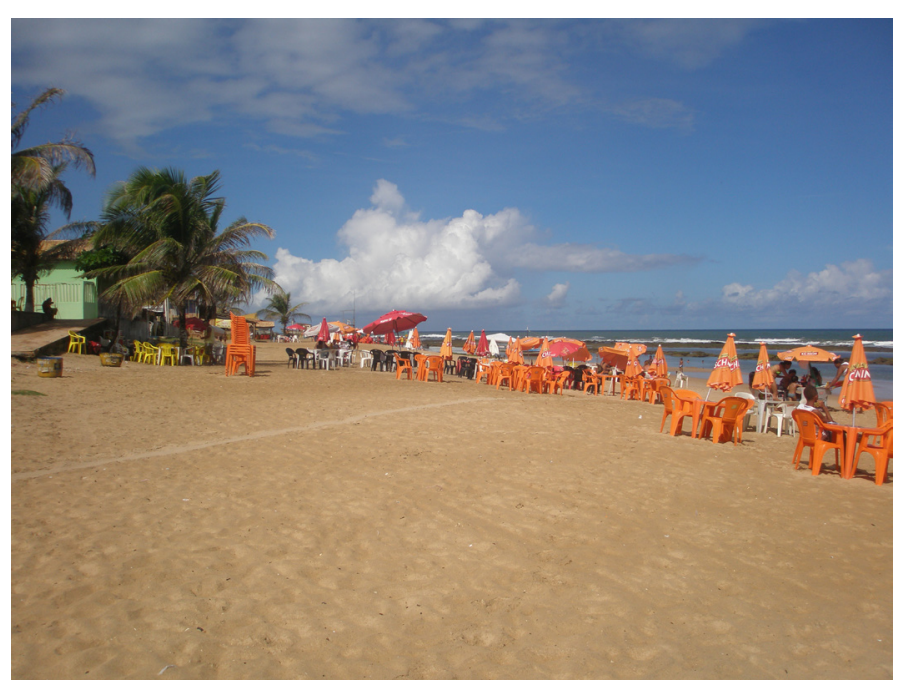

Figura 4. Praia de Subaúma - classificada como de alta qualidade recreacional.

Figure 4. Subaúma Beach - classified as "bigh recreational quality".

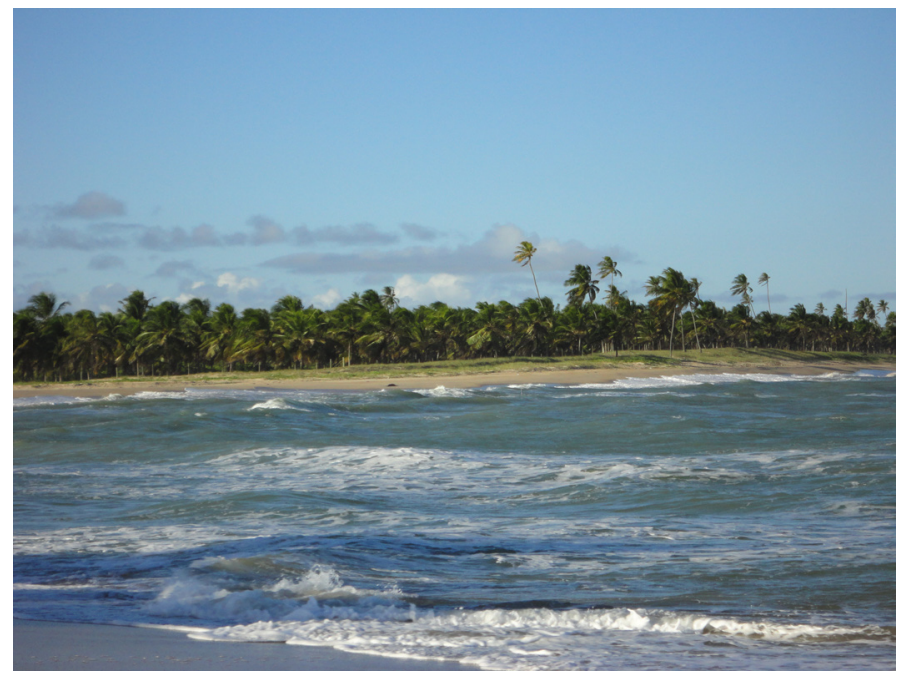

Figura 5. Ausência de infraestrutura recreacional na praia de Baixio.

Figure 5. Lack of recreational infrastructure on Baixio beach.

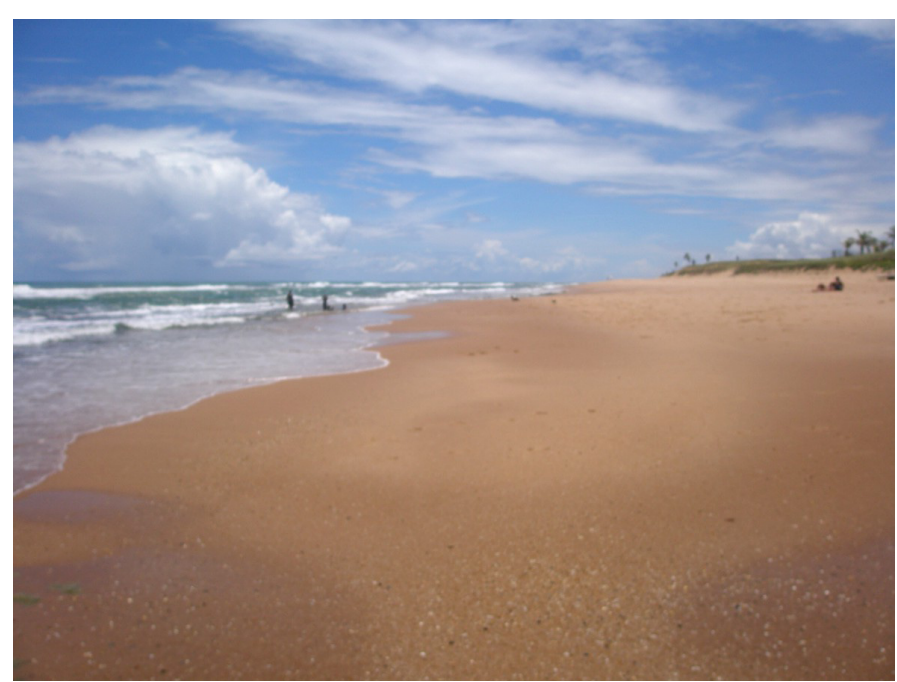

Figura 6. Ausência de infraestrutura recreacional na praia de Porto Sauípe.

Figure 6. Lack of recreational infrastructure on Porto Sauipe beach.

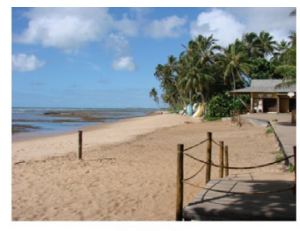

$8: 00 \mathrm{~h}$

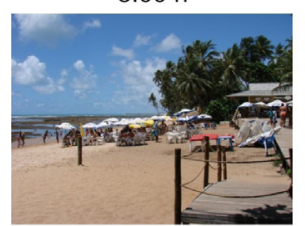

$11: 00 \mathrm{~h}$

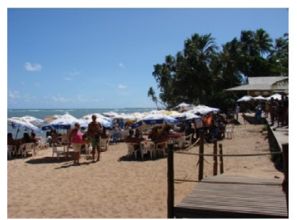

$14: 00 \mathrm{~h}$

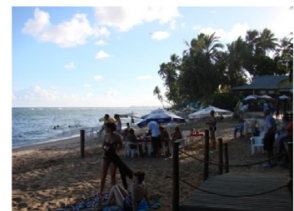

$17: 00 \mathrm{~h}$

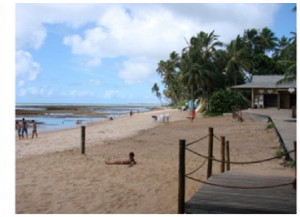

$9: 00 \mathrm{~h}$

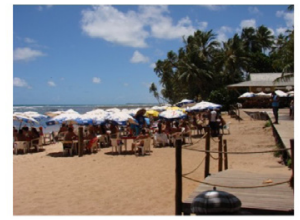

$12: 00 \mathrm{~h}$

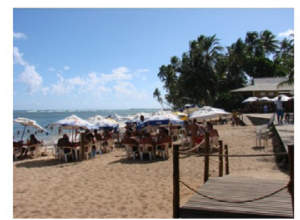

$15: 00 \mathrm{~h}$

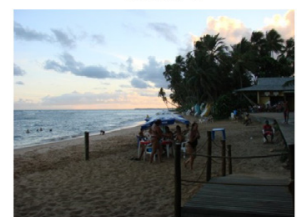

18:00 h

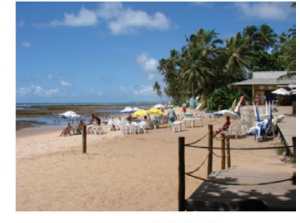

$10: 00 \mathrm{~h}$

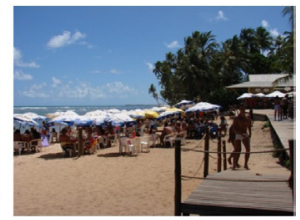

$13: 00 \mathrm{~h}$

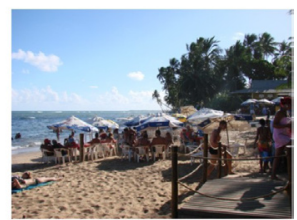

$16: 00 \mathrm{~h}$
Figura 7. Fluxo de usuários na Praia do Forte durante o período de 8 às 18:00h.

Figure 7. User dynamics in Praia do Forte beach between 8 a.m. and 6 p.m. 
Tabela 7. Área de praia disponível, nível de uso atual e capacidade de carga ideal para as praias da Costa dos Coqueiros.

Table 7. Beach area available, current use level and ideal carrying capacity Costa dos Coqueiros Beaches.

\begin{tabular}{|c|c|c|c|c|}
\hline Município & Praias & $\begin{array}{l}\text { Área de praia disponí- } \\
\text { vel para acomodaçáo } \\
\text { dos usuários }{ }^{*}\left(\mathbf{m}^{2}\right)\end{array}$ & $\begin{array}{c}\text { Nível de uso atual por praia } \\
\text { (área média utilizada por } \\
\text { banh./rec.) }\left(\mathrm{m}^{2}\right)(\mathrm{jan} / \mathrm{fev} \text { de } \\
2011)\end{array}$ & $\begin{array}{l}\text { Capacidade de } \\
\text { carga }\end{array}$ \\
\hline \multirow{3}{*}{ Lauro de Freitas } & Ipitanga & 50.000 & 5,5 & 5.000 \\
\hline & Vilas do Atlântico & 36.000 & 8 & 3.600 \\
\hline & Buraquinho & 17.500 & 10 & 1.750 \\
\hline \multirow{7}{*}{ Camaçari } & Busca Vida & 120.000 & 40 & 12.000 \\
\hline & Jauá & 100.000 & 4 & 10.000 \\
\hline & Interlagos & 60.000 & 70 & 6.000 \\
\hline & Arembepe & 195.000 & 2,4 & 19.500 \\
\hline & Barra do Jacuípe & 160.000 & 12 & 16.000 \\
\hline & Guarajuba & 180.000 & 6 & 18.000 \\
\hline & Itacimirim & 50.000 & 18 & 5.000 \\
\hline \multirow{4}{*}{ Mata de São João } & Praia do Forte & 72.000 & 13,5 & 7.200 \\
\hline & Imbassaí & 160.000 & 20 & 16.000 \\
\hline & Santo Antônio & 60.000 & $\mathrm{PD}^{* *}$ & 6.000 \\
\hline & Porto Sauípe & 165.000 & 60 & 16.500 \\
\hline \multirow[t]{2}{*}{ Entre Rios } & Massarandupió & 364.000 & $\mathrm{PD}$ & 36.400 \\
\hline & Subaúma & 159.000 & 20 & 15.900 \\
\hline Esplanada & Baixio & 501.000 & 25 & 50.100 \\
\hline \multirow{3}{*}{ Conde } & Barra do Itariri & 80.000 & 45 & 8.000 \\
\hline & Sítio do Conde & 475.000 & 50 & 47.500 \\
\hline & Siribinha & 125.000 & 60 & 12.500 \\
\hline \multirow[t]{2}{*}{ Jandaíra } & Costa Azul & 750.000 & $\mathrm{PD}$ & 75.000 \\
\hline & Mangue Seco & 280.000 & 40 & 28.000 \\
\hline
\end{tabular}

A área de praia disponível por usuário em Arembepe, nos locais de maior concentração (Fig. 8, Tabela 7), representa o menor valor encontrado nas praias da Costa dos Coqueiros, sendo inferior àqueles encontrados por Silva et al., (2009) para o trecho de maior concentração de usuários na praia de Itapoã, em Salvador (entre 4 e $10 \mathrm{~m}^{2} /$ pessoa), e por Silva et al., (2008), nas praias mais frequentadas de Porto Seguro, no sul da Bahia (entre 6 e $9 \mathrm{~m}^{2} /$ pessoa). É também inferior aos encontrados por Silva et al., (2006) na praia de Boa Viagem, em Recife (2,9 e $40,5 \mathrm{~m}^{2} /$ pessoa). Estes valores estão também fora do intervalo de conforto proposto por De Ruyck (1997) para praias da África do Sul (6,3 a $25 \mathrm{~m}^{2} /$ pessoa).
As praias com menor capacidade de carga social, estimada com base na área de praia disponível para acomodação dos usuários e na área ideal para uso, são as de Buraquinho, Vilas do Atlântico, Ipitanga, Itacimirim, Interlagos, Santo Antônio, Praia do Forte e Barra do Itariri todas com áreas disponíveis para acomodação na maré baixa inferiores a $100.000 \mathrm{~m}^{2}$ e com capacidades de carga inferiores a 10.000 pessoas/dia, considerando uma área ideal de $10 \mathrm{~m}^{2} /$ usuário (Tabela 7). Por outro lado, as praias com maior capacidade de carga são as de Massarandupió, Sitio do Conde, Baixio e Costa Azul, todas com áreas superiores a $300.000 \mathrm{~m}^{2} \mathrm{e}$ capacidades de carga acima de 30.000 usuários/dia (Tabela 7). Contudo, na maior parte da extensão destas quatro praias 


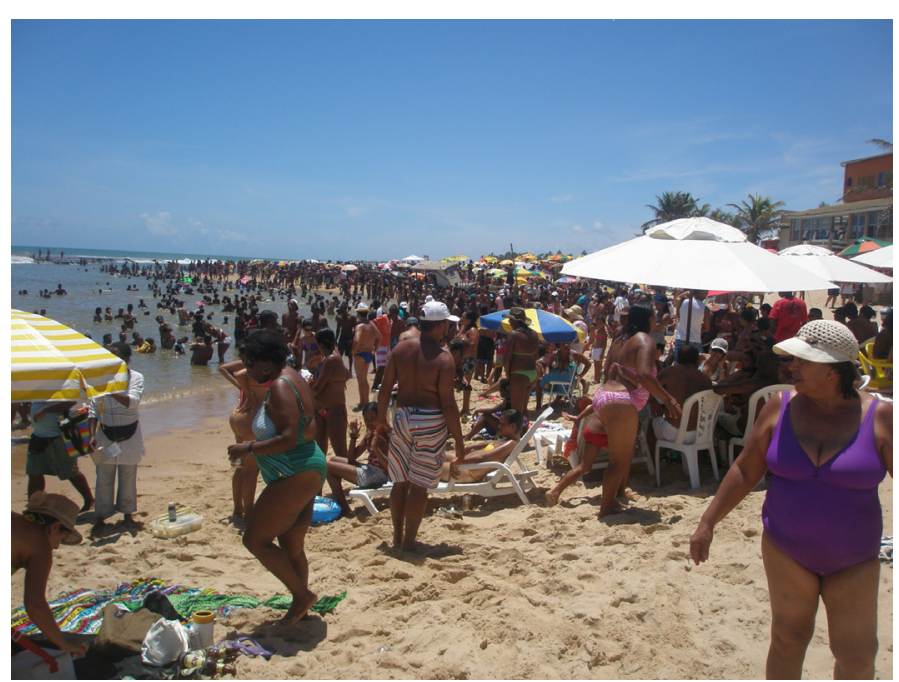

Figura 8. Uso intenso da praia de Arembepe.

Figure 8. Intensive use on Arembepe beach.

não existe atualmente nenhum tipo de ocupação, sendo áreas com imensas plantaçóes de coqueiros (Fig. 5) ou campos de duna que, em geral, concentram seus usuários apenas em um pequeno trecho, onde existem facilidades de acesso e infraestrutura.

Deve-se ainda salientar que, com relação à definição dos limites de cada praia, utilizados no cálculo da área disponível para acomodação dos usuários, existe normalmente uma dificuldade para estabelecer estes limites, seja em campo ou através de mapas, exceto quando estes são representados por algum elemento fisiográfico, como, por exemplo, no limite norte de Baixio (Fig. 1) (limite definido pelo rio Inhambupe). Esta dificuldade pode gerar uma imprecisão nos valores calculados (Tabela 7), como ocorreu, por exemplo, na definição do limite entre as praias de Massarandupió e Subaúma, entre Siribinha e Sitio do Conde e entre Costa Azul e Mangue Seco. Além disso, devido à escala regional $\mathrm{da}$ pesquisa, nomes locais (que não constam em mapas $\mathrm{e}$ guias do litoral) associados a um determinado trecho de uma praia não foram considerados, assim, por exemplo, a praia de Baixio foi delimitada ocupando todo o litoral do município de Esplanada.

\subsection{Limite Ecológico da Capacidade de Carga}

Ao longo do litoral em estudo é muito comum a substituiçáo da vegetaçáo original pela plantação de coqueiros, mantendo características de baixa urbanizaçáo, como ocorre, por exemplo, em quase toda a extensão do litoral entre Subaúma e Mangue Seco (Fig. 5) (Tabela 8).

Ao longo da Costa dos Coqueiros, construçóes fixas à beira-mar estâo presentes principalmente na praia de Ipitanga. Em Busca Vida, Jauá, Interlagos, Arembepe e Guarajuba elas ocorrem com percentuais entre 30 e $70 \%$ da extensão total da linha de costa (Fig. 9) (Tabela 8).

A ocorrência de ecossistemas sensíveis às açóes antropogênicas, como manguezais, recifes de corais, lagoas e dunas, associados à praia, são importantes indicadores de vulnerabilidade ambiental e sinalizam um limite ecológico mais restritivo. Os recifes de corais ocorrem entre as praias de Barra do Jacuípe e Praia do Forte (Leão, 1996), os manguezais ocorrem normalmente próximos às desembocaduras fluviais, as lagoas são comuns em diversos trechos do litoral, como em Guarajuba e Baixio, e as dunas apresentam uma maior ocorrência nas praias de Santo Antônio, Massarandupió, Costa Azul e Mangue Seco.

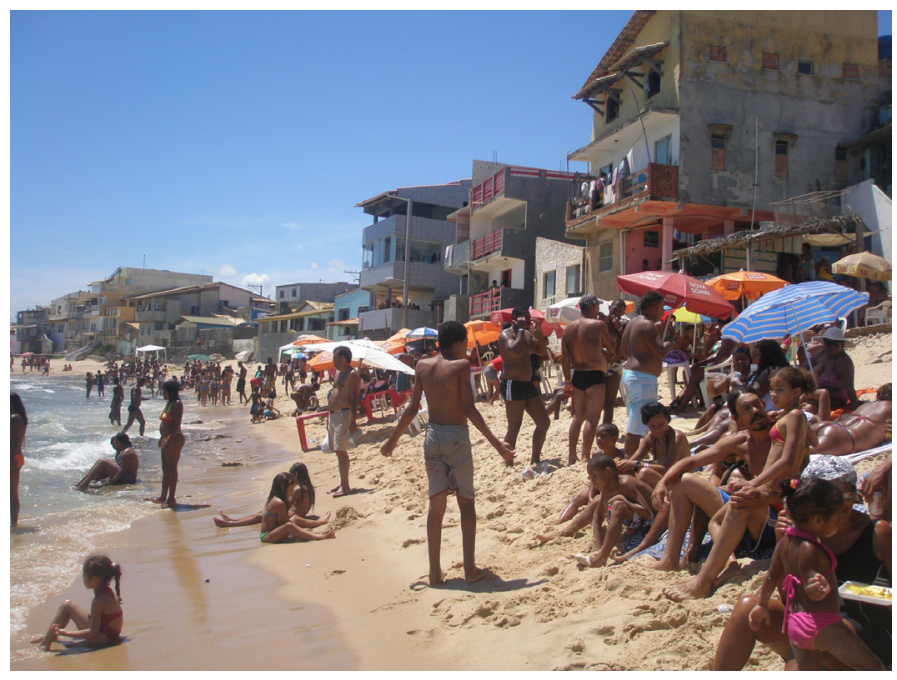

Figura 9. Construçóes fixas na praia de Arembepe.

Figure 9. Man-made structures on Arembepe beach.

As praias de Buraquinho, Barra do Jacuípe, Itacimirim, Praia do Forte, Imbassaí, Porto Sauípe, Massarandupió, Baixio, Barra do Itariri, Costa Azul e Mangue Seco apresentaram um limite ecológico mais restritivo para a capacidade de carga e apenas a praia de Ipitanga apresentou um limite ecológico menos restritivo. As demais praias da Costa dos Coqueiros apresentaram um limite ecológico intermediário (Tabela 8).

\section{CONCLUSÓES}

Ao longo da Costa dos Coqueiros foi constatado haver, de uma maneirageral, um notável paralelismo no comportamento das curvas de variação dos índices de qualidade geoambiental e de infraestrutura das praias entre Ipitanga e Baixio, o que não se observou entre Baixio e Mangue Seco (Fig. 2). No primeiro trecho, mais próximo a Salvador, maios populosos e acessível, apresenta também boas condiçóes geoambientais de suas praias, de uma maneira geral, o que atrairá assim uma maior demanda de usuários e, como decorrência, uma maior oferta de infraestrutura, circunstâncias essas inexistentes no segundo trecho.

Lembrando-se ainda, como dito anteriormente, que um aumento de infraestrutura normalmente vem acompanhado de maiores taxas de uso e maiores riscos de degradaçấo dos seus ecossistemas.

A avaliaçáo conjunta dos índices geoambientais e de infraestrutura indicou uma alta qualidade recreacional para 
Tabela 8. Limite ecológico para a capacidade de carga das praias da Costa dos Coqueiros (ver tabela 3).

Table 8. Ecological constraints for carrying capacity of Costa dos Coqueiros beaches (see Table 3).

\begin{tabular}{|c|c|c|c|c|}
\hline PRAIAS & $\begin{array}{l}\text { COBERTURA } \\
\text { VEGETAL }\end{array}$ & $\begin{array}{l}\text { CONSTRUÇÓES } \\
\text { FIXAS }\end{array}$ & $\begin{array}{l}\text { ECOSSISTEMAS } \\
\text { SENSÍVEIS }\end{array}$ & $\begin{array}{c}\text { LIMITE } \\
\text { ECOLÓGICO DA } \\
\text { CAPACIDADE DE } \\
\text { CARGA* }\end{array}$ \\
\hline Ipitanga & 3 & 3 & 3 & 9 \\
\hline Vilas do Atlântico & 2 & 1 & 3 & 6 \\
\hline Buraquinho & 2 & 1 & 2 & 5 \\
\hline Busca Vida & 2 & 2 & 2 & 6 \\
\hline Jauá & 2 & 2 & 2 & 6 \\
\hline Interlagos & 2 & 2 & 2 & 6 \\
\hline Arembepe & 2 & 2 & 3 & 7 \\
\hline Barra do Jacuípe & 2 & 1 & 2 & 5 \\
\hline Guarajuba & 2 & 2 & 2 & 6 \\
\hline Itacimirim & 2 & 1 & 2 & 5 \\
\hline Praia do Forte & 2 & 1 & 2 & 5 \\
\hline Imbassaí & 2 & 1 & 1 & 4 \\
\hline Santo Antônio & 2 & 1 & 2 & 5 \\
\hline Porto Sauípe & 2 & 1 & 2 & 5 \\
\hline Massarandupió & 2 & 1 & 2 & 5 \\
\hline Subaúma & 2 & 1 & 3 & 6 \\
\hline Baixio & 2 & 1 & 1 & 4 \\
\hline Barra do Itariri & 2 & 1 & 2 & 5 \\
\hline Sítio do Conde & 2 & 1 & 3 & 6 \\
\hline Siribinha & 2 & 1 & 3 & 6 \\
\hline Costa Azul & 2 & 1 & 2 & 5 \\
\hline Mangue Seco & 2 & 1 & 2 & 5 \\
\hline
\end{tabular}

* 3 a 5 - mais restritivo; 6 a 7 -intermediário; 8 a 9 - menos restritivo.

as praias de Vilas do Atlântico, Buraquinho, Itacimirim, Praia do Forte, Imbassaí e Subaúma e uma baixa qualidade recreacional para as praias de Busca Vida, Interlagos, Santo Antônio, Porto Sauípe, Massarandupió, Baixio e Sitio do Conde (Tabela 6).

As praias de Buraquinho, Vilas do Atlântico, Ipitanga, Itacimirim, Interlagos, Santo Antônio, Praia do Forte e Barra do Itariri apresentaram as menores áreas disponíveis para acomodação (inferiores a $100.000 \mathrm{~m}^{2}$ ) e capacidades de carga inferiores a 10.000 pessoas/dia, considerando uma área ideal de $10 \mathrm{~m}^{2}$ /usuário (Tabela 7). Já as praias de Massarandupió, Sitio do Conde, Baixio e Costa Azul apresentaram as maiores áreas disponíveis para acomodaçáo (supeiores a 300.000 $\mathrm{m}^{2}$ ) e capacidades de carga superiores a 30.000 usuários/dia (Tabela 7). As praias de Ipitanga, Arembepe, Jauá, Guarajuba e Vilas do Atlântico (Fig. 1), no que tange ao nível de uso atual, são as únicas do litoral norte que apresentaram valores de área disponível por usuário inferiores a $10 \mathrm{~m}^{2}$ (Fig. 8).

As praias que apresentaram um limite ecológico mais restritivo para a capacidade de carga (Buraquinho, Barra do Jacuípe, Itacimirim, Praia do Forte, Imbassaí, Porto Sauípe, Massarandupió, Baixio, Barra do Itariri, Costa Azul e Mangue Seco) (Tabela 8) devem, preferencialmente, experimentar maiores restriçóes de uso, evitando, por exemplo, o "turismo de massa" ou em grandes grupos, ou seja, vocacionando-as para outro tipo de turismo, como, por exemplo, o ecoturismo. Ademais, nestas praias devem ser respeitados os limites legais impostos pela Constituição do Estado da Bahia (Capítulo VIII) que proíbe qualquer construçáo, inclusive muros, numa faixa de $60 \mathrm{~m}$ a partir da linha de preamar máxima. 
Esta restrição deve ser observada especialmente para praias como Buraquinho, Itacimirim, Praia do Forte e Imbassaí que apresentaram um baixo limite ecológico (Tabela 8) e uma alta qualidade recreacional (Tabela 6), o que se reflete em uma alta demanda turística. Some-se a isso o fato de estas praias apresentarem uma baixa capacidade de carga (Tabela 7).

Outras praias, como Baixio e Costa Azul, ainda preservam suas características naturais, alteradas apenas pelas extensas plantaçóes de coqueiros, que ocupam quase todo o litoral de Subaúma a Mangue Seco (Fig. 9). Nestas praias, desertas ou semi-desertas, apesar de sua ampla capacidade de carga (acima de 50.000 pessoas por dia), seria recomendável gerenciá-las no sentido de restringir a sua capacidade de carga (ou seu nível de uso) devido ao seu limite ecológico ser baixo e, por isso, mais restritivo (Tabela 8). Em geral, a infraestrutura recreacional é muito precária nestas praias e a ocorrência de grandes ondas e correntes de retorno (Tabela 4) diminuem a sua segurança para banho. Por outro lado, a praia de Ipitanga, com características claramente urbanas, apresenta, entre todas as praias analisadas, o limite ecológico menos restritivo (Tabela 8), devendo-se atentar, contudo, para a sua baixa capacidade de carga (Tabela 7).

Por fim, acreditamos que os resultados do presente estudo poderão fornecer significativos subsídios para a gestão ambiental da Costa dos Coqueiros, auxiliando na tomada de decisóes a respeito de investimentos para o desenvolvimento do setor de turismo e sua compatibilização com as questóes relativas ao uso do solo.

\section{AGRADECIMENTOS}

Os autores agradecem à Fundação de Amparo à Pesquisa do Estado da Bahia (FAPESB) pelo financiamento da pesquisa e I. R. Silva e A. C. S. P. Bittencourt agradecem ao Conselho Nacional de Desenvolvimento Científico e Tecnológico (CNPq) pela Bolsa de Produtividade em Pesquisa.

\section{BIBLIOGRAFIA}

Alva, E.N. (2003) - Vetor Norte: um projeto de desenvolvimento sustentável para o Litoral Norte da Bahia. 65p, Fundação Onda Azul/MMA/Conder, Salvador, BA, Brasil. Disponível em http://www.ondazul.org.br/downloads/ arquivos $/ 25 . \mathrm{pdf}$

Araujo, M.C.B. de; Costa, M.F. (2008) - Environmental Quality Indicators for Recreational Beachs Classification. Journal of Coastal Research, 24(6):1439-1449, doi: 10.2112/06-0901.1.

Archer, B.; Cooper, C. (2001) - Os Impactos positivos e negativos do turismo. In: Theobald, W.F. (org.), Turismo Global, pp.10-20, Editora Senac, São Paulo, Brasil. ISBN: 8573591773.

Bittencourt, A.C.S.P.; Livramento, F.C.; Dominguez, J.M.L.; Silva, I.R. (2010) - Tendências de longo prazo à erosão costeira num cenário perspectivo de ocupação humana: litoral norte do estado da Bahia. Revista Brasileira de Geociências (ISSN: 2177-4382), 40(1):125-137. Disponível em http://ojs.c3sl.ufpr.br/ojs2/index.php/rbg/ article/view/14592/13311
Cin, R.D.; Simeoni, U. (1994) - A Model for Determining the Classification, Vulnerability and Risk in the Southern Coastal Zone of the Marche (Italy). Journal of Coastal Research, 10(1):18-29.

Coriolano, L.N.M.T.; Silva, S.B.M. (2005) - Turismo e Geografia: abordagens criticas. 173p., Editora UECE, Fortaleza, Brasil. ISBN: 8575642588

De Ruyck, M.C.; Soares, A.G.; McLachlan, A. (1997) - Social Carrying Capacity as a Management Tool for Sandy Beaches. Journal of Coastal Research, 13(3): 822-830.

Dominguez, J.M.L.; Andrade, A.C.S.; Almeida, A.B.; Bittencourt, A.C.S.P. (2009) - The Holocene Barrier Strandplains of the State of Bahia. In: Dillenburg, S. R. \& Hesp, P.A. (eds.), Geology and Geomorphology of Holocene Coastal Barriers of Brazil (Lecture Notes in Earth Sciences), pp. 253-288, Springer-Verlag, Berlin / Heidelberg, Alemanha. ISBN: 978-3540250081.

Dominguez, J.M.L.; Leão, Z.M.A.N.; Lyrio, R.S. (1996) - Litoral Norte do Estado da Bahia. XXXIV Congresso Brasileiro de Geologia, Roteiro de Excursão, 67p., Sociedade Brasileira de Geologia, São Paulo, SP, Brasil

Ergin, A.; Williams, A.T. \& Micaleff, A. (2006) - Coastal Scenery: Appreciation and Evaluation. Journal of Coastal Research, 22(4): 958-964. DOI: 10.2112/04-0351.1

Haggett, P. (2001) - Geography: A Global Synthesis. 4o edição, 833p., Prentice Hall, Harlow, Inglaterra. ISBN: 9780582320307.

Hall, C.M. (2001) - Trends in ocean and coastal tourism: the end of the last frontier? Ocean \& Coastal Management, 44(910):601-618. DOI: 10.1016/S0964-5691(01)00071-0

Leão, Z.M.A.N. (1996) - The coral reefs of Bahia: morphology, distribution and the major environmental impacts. Anais da Academia Brasileira de Ciências (ISSN: 0001-3765), 68(3):439-452, Rio de Janeiro, RJ, Brasil.

Leão, Z.M.A.N.; Kikuchi, R.K.P. (1999) - The Bahian Coral Reefs - from 7000 years BP to 2000 years AD. Ciência \& Cultura (ISSN 0009-6725), 51:262-273, Campinas, SP, Brasil.

Leatherman, S.P. (1997) - Beach Rating: A Methodological Approach. Journal of Coastal Research, 13(1):253-258.

Martin, L.; Bittencourt, A.C.S.P.; Vilas Boas G.S.; Flexor J.M. (1980) - Texto Explicativo para o Mapa Geológico do Quaternário Costeiro do Estado da Bahia. 57p, Companhia de Pesquisa Mineral, Secretaria de Minas e Energia, Salvador, BA, Brasil.

Midaglia, C.L.V. (2001) - Turismo e Meio Ambiente no Litoral Paulista: Dinâmica da Balneabilidade das Praias. In: Lemos, A.I.G. (ed.), Turismo: Impactos SócioAmbientais, pp-33-56, Editora Hucitec, São Paulo, Brasil. ISBN: 8527103435.

Morgan, R. (1999) - Preferences and Priorities of Recreational of Beach Users in Wales, UK. Journal of Coastal Research,15(3): 653-667.

Murphy, P.E. (2001) - Turismo e Desenvolvimento Sustentado. In: Theobald, W.F. (org.), Turismo Global. pp. 30-40, Editora Senac, São Paulo, Brasil. ISBN: 8573591773.

Polette, M.; Raucci, G.D. (2003) - Methodological Proposal for Carrying Capacity Analysis in Sandy Beaches: A Case Study at the Central Beach of Balneário Comboriú (Santa 
Catarina, Brazil). Journal of Coastal Research, SI35:94106.

Silva, C. Pereira da (2002) - Beach Carrying Capacity Assessment: How important is it? Journal of Coastal Research, SI36:190-197.

Silva, I.R.; Bittencourt, A.C.S.P.; Dominguez, J.M.L.; Silva, S.B.M. (2003) - Uma Contribuiçãoo à Gestão Ambiental da Costa do Descobrimento (Litoral Sul do Estado da Bahia): Avaliação da Qualidade Recreacional das Praias. Geografia (0100-7912), 28: 397-413, Rio Claro, SP, Brasil.

Silva, I.R.; Bittencourt, A.C.S.P.; Dominguez, J.M.L.; Silva, S.B.M. (2007) - Potencial de Danos Econômicos Face à Erosão Costeira, Relativo às Praias da Costa do Descobrimento - Litoral Sul do Estado da Bahia. Pesquisas em Geociências (ISSN 1807-9806), 34(1):3544, Porto Alegre, RS, Brasil. Disponível em http://www. pesquisasemgeociencias.ufrgs.br/3401/03-3401.pdf

Silva, I.R.; Bittencourt, A.C.S.P.; Silva, S.B.M.; Dominguez, J.M.L; Souza Filho, J.R. (2008) - Nível de antropização X nível de uso das praias de Porto Seguro/BA: subsídios para uma avaliação da capacidade de suporte. Revista de Gestão Costeira Integrada, 8(1):1-13. http://www.aprh.pt/ rgci/pdf/revista8f1_5.pdf

Silva, I.R.; Souza Filho, J.R.; Barbosa, M.; Rebouças, F.; Machado, R.S. (2009) - Diagnóstico Ambiental e
Avaliação da Capacidade de Suporte das Praias do Bairro de Itapoã, Salvador, Bahia. Revista Sociedade e Natureza (1982-4513), 21(1):71-84, Uberlândia. MG, Brasil.

Silva, J.S.; Barbosa, S.C.T.; Leal, M.M.V.; Lins, A.R.; Costa, M.F. (2006) - Ocupação da praia da Boa Viagem (Recife/ $\mathrm{PE})$ ao longo de dois dias de veráo: um estudo preliminar. Pan-American Journal of Aquatic Sciences (ISSN: 18099009), 1(2):91-98.

Silva, S.B.M.; Silva, B.C.N.; Carvalho, S.S. (2008) Metropolização e turismo no litoral norte de Salvador: de um deserto a um território de enclaves? In: Carvalho, I. \& Pereira, G.C. (org.), Como anda Salvador e sua Região Metropolitana, pp. 189-211, Edufba, Salvador, BA, Brasil. ISBN: 8523203931. Disponível on-line em http://ufba. academia.edu/GilbertoCorso/Books/933296/Como_ Anda_Salvador.

Suguio, K.; Nogueira, A.C.R. (1999) - Revisão Crítica dos Conhecimentos Geológicos sobre a Formação (ou Grupo?) Barreiras do Neógeno e o seu Possível Significado como Testemunho de Alguns Eventos Geológicos Mundiais. Geociências (ISSN: 1980-900X), 18:461-479, Rio Claro, SP, Brasil.

Williams, P.W.; Gill, A. (2001) - Questôes de Gerenciamento da Capacidade de Carga Turística. In: Theobald, W.F. (org.), Turismo Global, pp. 45-55, Editora Senac, São Paulo, Brasil. ISBN: 8573591773. 